\title{
Predicting the geographic distribution of Lutzomyia longipalpis (Diptera: Psychodidae) and visceral leishmaniasis in the state of Mato Grosso do Sul, Brazil
}

\author{
Paulo Silva de Almeida, ${ }^{1,3}$, Alan Sciamarelli', Paulo Mira Batista², Ademar Dimas Ferreira3 \\ João Nascimento ${ }^{3}$, Josué Raizer ${ }^{1}$, José Dilermando Andrade Filho ${ }^{4}$, Rodrigo Gurgel-Gonçalves ${ }^{5}+{ }^{+}$ \\ ${ }^{1}$ Faculdade de Ciências Biológicas e Ambientais, Universidade Federal da Grande Dourados, Dourados, MS, Brasil \\ ${ }^{2}$ Gerência de Zoonoses, Diretoria Geral de Vigilância em Saúde ${ }^{3}$ Coordenadoria de Controle de Vetores, Secretaria de Estado de Saúde, \\ Campo Grande, MS, Brasil ${ }^{4}$ Centro de Pesquisas René Rachou-Fiocruz, Belo Horizonte, MG, Brasil \\ ${ }^{5}$ Laboratório de Parasitologia Médica e Biologia de Vetores, Faculdade de Medicina, Universidade de Brasília, Brasília, DF, Brasil
}

To understand the geographic distribution of visceral leishmaniasis (VL) in the state of Mato Grosso do Sul (MS), Brazil, both the climatic niches of Lutzomyia longipalpis and VL cases were analysed. Distributional data were obtained from 55 of the 79 counties of MS between 2003-2012. Ecological niche models (ENM) of Lu. longipalpis and $V L$ cases were produced using the maximum entropy algorithm based on eight climatic variables. Lu. longipalpis showed a wide distribution in MS. The highest climatic suitability for Lu. longipalpis was observed in southern MS. Temperature seasonality and annual mean precipitation were the variables that most influenced these models. Two areas of high climatic suitability for the occurrence of VL cases were predicted: one near Aquidauana and another encompassing several municipalities in the southeast region of MS. As expected, a large overlap between the models for Lu. longipalpis and VL cases was detected. Northern and northwestern areas of MS were suitable for the occurrence of cases, but did not show high climatic suitability for Lu. longipalpis. ENM of vectors and human cases provided a greater understanding of the geographic distribution of VL in MS, which can be applied to the development of future surveillance strategies.

Key words: Lutzomyia longipalpis - visceral leishmaniasis - Maxent - climatic niches

Visceral leishmaniasis (VL) is a severe systemic disease resulting from infection with Leishmania infantum (syn. Leishmania chagasi). In the Americas, domestic dogs are the main reservoirs of the parasite, which is transmitted mainly by Lutzomyia longipalpis (Diptera: Psychodidae) (Gontijo \& Melo 2004), a synanthropic sandfly species with a wide geographic distribution in Brazil (Souza et al. 2009). Between 2003-2007, approximately 3,500 VL cases were reported per year in Brazil, which corresponds to $95 \%$ of all new cases of VL in the Americas (Alvar et al. 2012). Control measures directed against sandflies have been unsuccessful and the early detection and treatment of human cases remains the most important strategy for reducing case fatalities (Romero \& Boelaert 2010).

In the state of Mato Grosso do Sul (MS), VL was restricted to the municipalities of Corumbá and Ladário until 1993 (Antonialli et al. 2007), but its presence is currently registered in 41 municipalities. An increase in the number of cases diagnosed in urban centres was observed, reflecting both disease expansion and urbanisation in the state as well as representing a threat to public health, considering the mean disease lethality

doi: 10.1590/0074-0276130331

Financial support: CAPES

+ Corresponding author:rgurgel@unb.br

Received 22 June 2013

Accepted 29 October 2013 of 7.8\% (Oliveira et al. 2006b). The Notifiable Diseases Information System recorded 1,919 cases of VL in MS between 2003-2011, which represents 75\% of all cases recorded in Central-West Brazil. Most cases occurred in the municipalities of Aquidauana, Campo Grande and Três Lagoas, which are currently classified as areas of intense transmission of $\mathrm{VL}$, where $\mathrm{Lu}$. longipalpis has also been detected (Silva et al. 2007, MS/SVS 2013).

The geographic distribution of $L u$. longipalpis extends from Mexico to Argentina (Deane \& Deane 1962, Sherlock 1996, Souza et al. 2009, Salomón et al. 2011). This species occurs in areas with different climatic conditions, ranging from the semi-arid areas in the Caatin$g a$ biome to wetter areas in other Brazilian biomes and presents great adaptability to different habitats and environmental changes (Ximenes et al. 2000, Aguiar et al. 2003, Missawa \& Lima 2007). In MS, Lu. longipalpis is the primary species captured in anthropic environments (Oliveira et al. 2006b, Almeida et al. 2010a, b) and is the principal vector of $L$. infantum. Transmission, however, can occur by Lutzomyia cruzi in Corumbá in northwest MS (Santos et al. 1998).

Ecological niche models (ENM) have been used to predict the occurrence areas of sandflies and leishmaniasis in Brazil. Peterson and Shaw (2003) predicted climate change effects on Nyssomyia whitmani distribution; specifically, under climate change scenarios, an extension of the geographic range of Ny. whitmani was predicted in Southeast Brazil, where cutaneous leishmaniasis appears to be re-emerging. Peterson et al. (2004) demonstrated that elevation and vegetation significantly 
influence the distribution of sandflies in the state of São Paulo (SP). In the state of Bahia, predictive models estimated a higher incidence of VL in hot and dry areas (Caatinga), whereas areas of Cerrado and the Atlantic Forest were considered to be less suitable for disease transmission (Nieto et al. 2006). Through logistic regression, Zeilhofer et al. (2008) demonstrated that the spatial distribution of $\mathrm{Ny}$. whitmani is associated with deforestation and with lower rates of gross domestic product in the state of Mato Grosso (MT).

Given the proven usefulness of spatial modelling techniques in understanding the distribution of sandflies and leishmaniasis and the fact that the predictive analysis of the geographic distribution of Lu. longipalpis and human cases of VL can aid in the development of monitoring and disease control programs in MS, the present study aims to analyse the climatic conditions of the occurrence areas of Lu. longipalpis and VL cases using ecological niche modelling.

\section{MATERIALS AND METHODS}

MS is located in the Central-West Region of Brazil, with an area of $358,200 \mathrm{~km}^{2}$. It borders the states of Minas Gerais, SP and Paraná to the east and MT and Goiás to the north. Moreover, MS has international borders with Bolivia and Paraguay. The state has 78 counties, divided into 11 micro-regions, with a population of approximately two million inhabitants (IBGE/MPOG 2010). The Sedimentary Plateau Basin of the Paraná River and the South Pantanal Plains are the major geological units in MS. The biomes present in the state are the Cerrado, Pantanal and Atlantic Forests.

The climate of MS, according to the Köppen classification, varies between the Aw (tropical humid climate with a rainy summer and a dry winter) and the $\mathrm{Cfa}$ (humid mesothermal climate with no dry season) subtypes, with temperatures during the warmest month reaching over $22^{\circ} \mathrm{C}$ and with low precipitation during its driest month. In MS, there is predominance of undulated elevation and of Oxisols (IBGE 1990).

Distributional data for Lu. longipalpis were obtained from entomological surveys carried out by the Sector of Entomology of the Vector Control Coordination of the State Department of Health and from entomology laboratories of the respective municipalities. The research was conducted between 2003-2012 in urbanised areas of 55 municipalities of MS, corresponding to $70 \%$ of the counties in this state. Samples were collected with CDC light traps that were installed at dusk inside houses and in domestic animal shelters (peridomiciles) and collections took place over a period of $12 \mathrm{~h}$ for three consecutive nights. In 23 of the 55 municipalities (42\%), a survey of sandflies was performed via entomological monitoring over two years following the methods described in Almeida et al. (2010b). The number of points sampled varied among municipalities depending on the urban total area (between 4-12 sampling points), with capture effort ranging from 96-1,728 traps by municipality. For other municipalities, entomological surveys were conducted with an average capture effort of 50 traps. For identification of sandfly species, specific keys were used
(Galati 2003). Sandfly specimens were deposited in the Regional Laboratory of Entomology of Dourados, MS. The presence of $L u$. longipalpis was recorded in 118 sites and their georeferencing had a precision of $0.0001^{\circ}$.

The present study included records of VL cases reported by local health services in the municipalities of MS during 2003-2012. The cases were georeferenced according to the coordinates of the municipality administrative centre with a reasonable degree of confidence (i.e., with an uncertainty of $\leq 5 \mathrm{~km}$, to a precision of \pm $0.01^{\circ}$ ). All records were georeferenced based on a consultation of Brazilian Institute of Geography and Statistic (IBGE) (ibge.gov.br/).To characterise climatic variation across MS, eight climatic variables were used: annual mean temperature, diurnal temperature range, temperature seasonality, maximum temperature in the warmest month, minimum temperature in the coldest month, annual precipitation, precipitation in the wettest month and precipitation in the driest month. These variables were obtained from the WorldClim project (worldclim.org) and were developed via the interpolation of mean monthly climatic data from meteorological stations over 30-50 years (1950-2000), depending on data availability at stations (Hijmans et al. 2005). These variables were selected to avoid the confounding effects of calibrating models in an overly dimensional environmental space (Peterson \& Nakazawa 2008). The climatic database used in the analysis presented a spatial resolution of $5 \times 5 \mathrm{~km}$ per pixel.

Models were produced using Maxent v.3.2.1 (Phillips et al. 2006), applying default parameters with the exception that we chose a random seed, with 10 replicate analyses based on bootstrap subsampling. We used the median output grids as the best hypothesis of potential range and imported them into ArcView v.3.3 for assessment and analysis. Distributional data for Lu. longipalpis and human cases of VL were separated into two sets: one for model calibration ( $75 \%$ of points) and the other for model evaluation ( $25 \%$ of points). For Lu. longipalpis, several sites were near one another and the model was produced by using a reduced number of spatially unique points, considering the spatial resolution of our data.

The quality of the models generated was evaluated using the receiver operating characteristics (ROC) curve, which correlates the sensitivity and specificity of model predictions across multiple thresholds (Phillips et al. 2006). The area under the ROC curve (AUC) provides a measure of model performance across many thresholds. AUC values close to one indicate high performance, whereas readings below 0.5 indicate the poor performance of a model (Elith et al. 2006). Model accuracy was assessed by examining the omission rates associated with test points (Anderson et al. 2002) and Maxent's jackknife test was used to identify variables that most influence model predictions. The contribution of each variable to the model was estimated through the permutation importance provided by Maxent (Phillips et al. 2006). To test model significance, we compared the predictive success of the models against null expectations using a cumulative binomial test. In particular, we assessed whether each test point fell in the areas that were identified by the model as suitable and compared this success rate with 
overall proportions of pixels identified as suitable or unsuitable for that species.

Finally, to analyse the overlapping area between the models of Lu. longipalpis and VL cases, the raw Maxent outputs were converted into binary maps showing the presence or absence based on a threshold of 0.60 (values above this threshold were considered presence and they represented higher climate suitability). Then, the overlapping area was calculated using the ArcView Spatial Analyst extension.

\section{RESULTS}

Lu. longipalpis occurred in 37 (67\%) of the 55 municipalities surveyed. The predictive model indicated wide potential distribution of Lu. longipalpis in MS. The highest climatic suitability for Lu. longipalpis was observed in the south of the state (Fig. 1). Lu. longipalpis was not registered in areas with high climatic suitability for vector occurrence in several municipalities of MS, such as Navirai, Itaquira and Juti. Temperature seasonality and annual mean precipitation were the variables that most influenced the distribution of Lu. longipalpis (Maxent's permutation importance $=79.7$ and 4.9, respectively). The model revealed $0 \%$ error of omission and AUC $=0.992$ and was statistically significant $(\mathrm{p}<$ 0.01 ) as indicated by the binomial test.

Two areas of high climatic suitability for the occurrence of VL cases were predicted: one near Aquidauana, Dois Irmãos do Buriti and Anastácio and another encompassing several municipalities in the southeast region of the state, such as Nova Alvorada do Sul, Angélica and Jatei (Fig. 1). Temperature seasonality and precipitation of the driest month were the variables that most influenced models of VL cases (Maxent's permutation importance $=67.4$ and 7.3, respectively). The model showed $0 \%$ error of omission and AUC $=0.991$ and was also statistically significant $(\mathrm{p}<0.01)$.
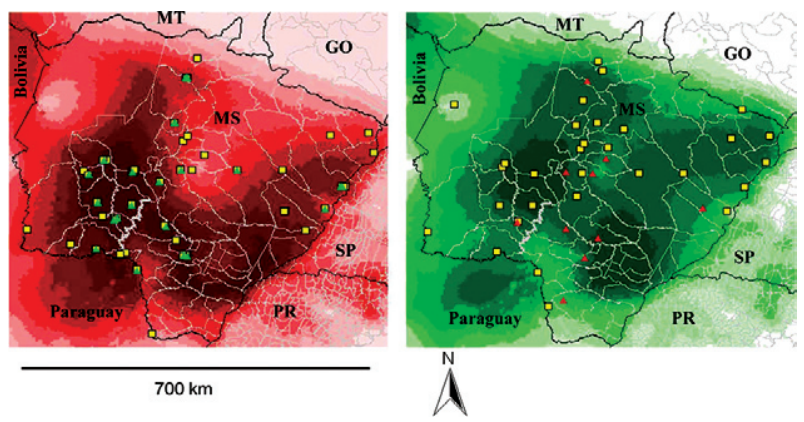

Fig 1: ecological niche models projected for the potential distribution of Lutzomyia longipalpis (left) and human cases of visceral leishmaniasis (right). Areas identified as suitable based on the records of the occurrence of Lu. longipalpis are shown on a red scale: light red (low suitability) to dark red (high suitability), while areas identified as suitable based only on VL cases are presented on a green scale: light green (low suitability) to dark green (high suitability). The lines indicate the political boundaries of the states and its respective municipalities (GO: state of Goiás; MS: state of Mato Grosso do Sul; MT: state of Mato Grosso; PR: state of Paraná; SP: state of São Paulo). The records used to calibrate the models are represented by squares, while the records used to test the models are represented by triangles.
A large area of overlap between the models of $L u$. longipalpis and VL cases was detected. When considering all values of climatic suitability of the VL and $L u$. longipalpis models, $100 \%$ of MS territory was suitable for the occurrence of vector and disease (Fig. 1). However, the northern and northwestern areas of MS were suitable for the occurrence of cases and did not show high climatic suitability for the occurrence of $\mathrm{Lu}$. longipalpis. By superimposing the models of VL cases and Lu. longipalpis, considering the higher values of climatic suitability $(>0.60)$, areas climatically more favourable for the occurrence of Lu. longipalpis and VL cases were observed, representing $41 \%$ of MS territory (Fig. 2). This overlapping area included most municipalities of intense VL transmission (e.g., Aquidauana, Anastácio, Campo Grande, Três Lagoas) and several vulnerable municipalities for VL transmission in southeast MS (Fig. 2).

\section{DISCUSSION}

Predictive models indicated that almost the entire territory of MS has the potential for VL occurrence. In areas more suitable for the occurrence of VL cases and less suitable for the occurrence of Lu. longipalpis, transmission is possible by Lu. cruzi (Santos et al. 1998). This scenario should occur in Corumbá (northwest MS) and three other municipalities in northern MS (e.g., São Gabriel do Oeste, Camapuã and Cassilândia) where $L u$. cruzi was detected. The models also indicated that in southern areas of MS, there is high climatic suitability for the occurrence of Lu. longipalpis, although the species has only been recorded in one municipality based on
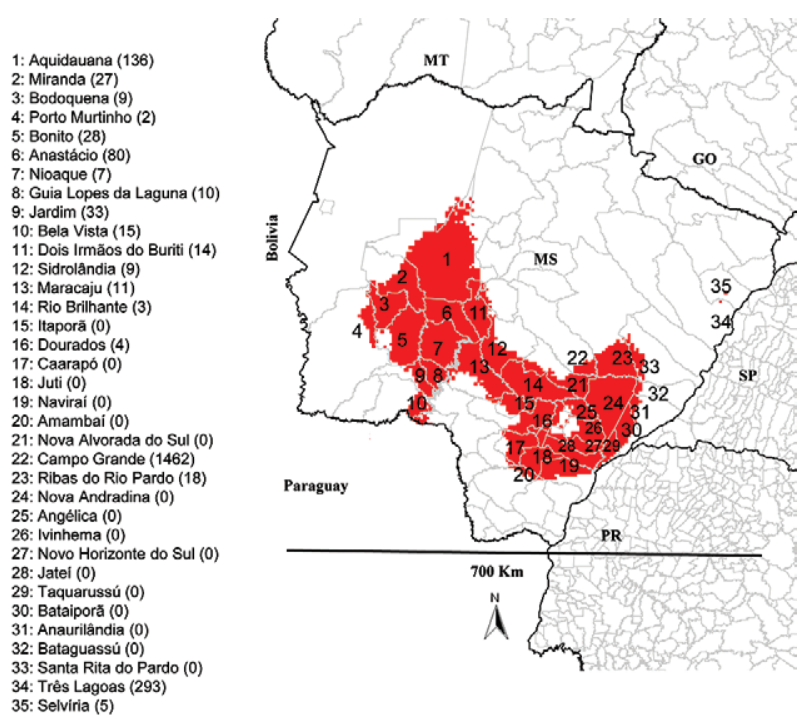

Fig 2: overlapping ecological niche models of Lutzomyia longipalpis and human cases of visceral leishmaniasis (VL) in Mato Grosso do Sul (MS). The overlapping area is shown in red. The white areas indicate the absence or predicted climatic suitability smaller values (values $<$ 0.60 ). The lines indicate the political boundaries of the states and its respective municipalities (GO: state of Goiás; MS; MT: state of Mato Grosso; PR: state of Paraná; SP: state of São Paulo). The numbers indicate the name of the municipalities of MS and the numbers between parentheses indicate notified human cases of VL in MS (2003-2012). 
conducted entomological research. This result illustrates a practical application of ecological niche modelling by indicating suitable municipalities for vector occurrence in cases of entomological research with low capture effort or even unrealised sampling.

Lu. longipalpis was the most abundant species in the anthropic environment in municipalities of MS such as Campo Grande, where an increase of 60 times in the density of this species was registered compared to the last sandfly evaluation in 1999/2000 (Oliveira et al. 2006a). The factors associated with the increase in the occurrence and abundance of Lu. longipalpis in MS are only partially understood. Oliveira et al. (2012) found a significant positive linear correlation between the abundance of Lu. longipalpis and the percentage of vegetation cover; moreover, these researchers observed the highest abundance of sandflies in houses with chickens. The attractiveness of chickens to sandflies has often been described (Lainson \& Rangel 2005).

Spatial analysis of VL in MS indicated that the expansion route of the disease has been from west to east, coinciding with the routes of three anthropogenic disturbances of the environment, such as the construction of a gas pipeline that began in 1998 and a federal highway and railroad that were constructed in the early XX century (Antonialli et al. 2007). The authors hypothesise that the intense migration of workers from the VL endemic region in the city of Corumbá explains the new epidemiological pattern of the establishment of this disease in MS. Our study indicated two areas of high climatic suitability for the occurrence of VL cases. The area near Aquidauana, Dois Irmãos do Buriti and Anastácio coincides with high predicted VL incidence rates in MS based on geostatistical models (Karagiannis-Voules et al. 2013). The incidence of VL in southeast MS is still low, but the present study indicates that climatic conditions are favourable for the occurrence of Lu. longipalpis in this area. Thus, municipalities near Nova Alvorada do Sul, Angélica and Jatei should be monitored.

The influence of climatic variables on the occurrence of sandflies and VL has been observed in other studies (Franke et al. 2002, Peterson \& Shaw 2003). In this study, the variable that most influenced the models was temperature seasonality. Quintana et al. (2013) noted that precipitation seasonality and precipitation in the warmest quarter were the variables that most contributed to the ENM of Lutzomyia neivai and Lutzomyia migonei in Argentina. These variables, as well as temperature seasonality, are indicative of areas with well-defined dry and rainy seasons. In Brazil, the majority of VL cases have been recorded in northeastern and Central-West Brazil (MS/SVS 2013), which present a well-defined dry season. Ecological studies of sandflies in this region have indicated that the population density of these insects increases after the end of the rainy season (Sherlock 1996), which has also been observed for Lu. longipalpis in MS (Oliveira et al. 2003, Almeida et al. 2010a).

Other variables, such as deforestation and socioeconomic factors, which have been linked to the occurrence of other sandfly species (Zeilhofer et al. 2008), may also influence the occurrence of $L u$. longipalpis. Environmen- tal disturbances, rural-urban migration, increased population density, a higher amount of solid waste production without proper destination and the close proximity of residents to domestic animals are some of the factors that may facilitate the urbanisation of VL in municipalities with more than 100,000 inhabitants (MS 2006).

A limitation of the niche model for VL cases in MS was the use of the coordinates of the municipality administrative centre. A more refined analysis could be performed with the geographical coordinates of all confirmed human cases of VL in MS. Unfortunately, this information was not available for the present study. Future studies based on the specific location where infection occurred would increase the number of records analysed and allow for a better comparison between niche models of vector species and the occurrence of human cases. Moreover, studies analysing the effects of deforestation and demographic and socioeconomic variables for the occurrence of Lu. longipalpis and VL in MS may improve the predictive models presented in our study and aid in understanding the geography of disease transmission in the state. Analysis with higher spatial resolution, considering niche characteristics over future climate change scenarios (Moo-Llanes et al. 2013) and using different spatial analysis (Sarkar et al. 2010, Karagiannis-Voules et al. 2013), may refine the predictive models presented to better assess the risk factors for transmission of VL in MS.

Species distribution models may contribute to the planning of measures designed to control vector-borne diseases. Modelling enables the development of geographic predictions of pathogens transmitted by insect vectors, with important implications for human health. Accordingly, the methodological approach presented here may serve as a model for studies in other Brazilian states. ENM of vectors and human cases allows for a better understanding of the geographic distribution of VL in MS, which can be applied to the development of future strategies for the surveillance and control of this disease.

\section{ACKNOWLEDGEMENTS}

To the technicians of the Entomology Technical Coordination of the Vectors Control Department/SES who participated in phlebotomine sampling in MS, and to Dr Gustavo AS Romero, for reviewing the paper.

\section{REFERENCES}

Aguiar GM, Medeiros WM 2003. Distribuição regional e habitats das espécies de flebotomíneos do Brasil. In Flebotomíneos do Brasil, Fiocruz, Rio de Janeiro, p. 207-255.

Almeida PS, Minzão ER, Minzão L, Silva SR, Ferreira AD, Faccenda O, Andrade Filho JD 2010a. Aspectos ecológicos de flebotomíneos (Diptera: Psychodidae) em área urbana do município de Ponta Porã, estado de Mato Grosso do Sul. Rev Soc Bras Med Trop 43: 723-727.

Almeida PS, Nascimento JC, Ferreira AD, Minzão LD, Portes F, Miranda AM, Faccenda O, Andrade Filho JD 2010b. Espécies de flebotomíneos (Diptera, Psychodidae) coletadas em ambiente urbano em municípios com transmissão de leishmaniose visceral do estado de Mato Grosso do Sul, Brasil. Rev Bras Entomol 54: 304-310.

Alvar J, Vélez ID, Bern C, Herrero M, Desjeux P, Cano J, Jannin J, den Boer M, WHO Leishmaniasis Control Team 2012. Leishma- 
niasis worldwide and global estimates of its incidence. PLOS ONE 7: e35671.

Anderson RP, Gómez-Laverde M, Peterson AT 2002. Geographical distributions of spiny pocket mice in South America: insights from predictive models. Global Ecol Biogeogr 11: 131-141.

Antonialli SAC, Torres TG, Paranhos Filho AC, Tolezano JE 2007. Spatial analysis of American visceral leishmaniasis in Mato Grosso do Sul state, central Brazil. J Infect 54: 509-514.

Deane LM, Deane MP 1962. Visceral leishmaniasis in Brazil: geographical distribution and transmission. Rev Inst Med Trop $S$ Paulo 4: 198-212.

Elith JC, Graham C, Anderson R, Dudík M, Ferrier S, Guisan A, Hijmans R, Huettmann F, Leathwick J, Lehmann A, Li J, Lohmann L, Loisell B, Manion G, Moritz C, Nakamura M, Nakazawa Y, Overton J, Peterson AT, Phillips S, Richardson K, ScachettiPereira R, Schapire E, Soberón J, Williams S, Wisz M, Zimmerman N 2006. Novel methods improve prediction of species distributions from occurrence data. Ecography 29: 129-151.

Franke CR, Ziller M, Staubach C, Latif M 2002. Impact of the El Niño/southern oscillation on visceral leishmaniasis, Brazil. Emerg Infect Dis 8: 914-917.

Galati EAB 2003. Classificação de Phlebotominae. In Flebotomíneos do Brasil, Fiocruz, Rio de Janeiro, p. 23-51.

Gontijo CMF, Melo NM 2004. Leishmaniose visceral no Brasil: quadro atual, desafios e perspectivas. Rev Bras Epidemiol 7: 338-346.

Hijmans J, Cameron SE, Parra JL, Jones PG, Jarvis A 2005. Very high resolution interpolated climate surfaces for global land areas. Int J Climatol 25: 1965-1978.

IBGE - Instituto Brasileiro de Geografia e Estatística 1990. Atlas multireferencial: Mato Grosso do Sul, MS/SEPLAN, Campo Grande, 28 pp.

IBGE/MPOG - Instituto Brasileiro de Geografia e Estatística/Ministério do Planejamento, Orçamento e Gestão 2010. Relatório de gestão 2010. Available from: ibge.gov.br/estadosat/perfil.php?sigla $=\mathrm{ms}$.

Karagiannis-Voules DA, Scholte RGC, Guimarães LH, Utzinger J, Vounatsou P 2013. Bayesian geostatistical modeling of leishmaniasis incidence in Brazil. PLoS Negl Trop Dis 7: e2213.

Lainson R, Rangel EF 2005. Lutzomyia longipalpis and the eco-epidemiology of American visceral leishmaniasis, with particular reference to Brazil - A Review. Mem Inst Oswaldo Cruz 100: 811-827.

Missawa NA, Lima GBM 2007. Distribuição de Lutzomyia longipalpis (Lutz \& Neiva, 1912) e Lutzomyia cruzi (Mangabeira, 1938) no estado de Mato Grosso. Rev Soc Bras Med Trop 39: 337-340.

Moo-Llanes D, Ibarra-Cerdeña CN, Rebollar-Téllez EA, Ibáñez-Bernal S, González C, Ramsey JM 2013. Current and future niche of North and Central American sandflies (Diptera: Psychodidae) in climate change scenarios. PLoS Negl Trop Dis 7: e2421.

MS - Ministério da Saúde 2006. Manual de vigilância e controle da leishmaniose visceral, MS, Brasília, 120 pp.

MS/SVS - Ministério da Saúde/Secretaria de Vigilância em Saúde 2013. Leishmaniose visceral. Aspectos epidemiológicos. Available from: portal.saude.gov.br/portal/saude/profissional/area. cfm?id_area $=1561$.

Nieto P, Malone JB, Bavia ME 2006. Ecological niche modeling for visceral leishmaniasis in the state of Bahia, Brazil, using genetic algorithm for rule-set prediction and growing degree day-water budget analysis. Geospat Health 1: 115-126.

Oliveira AG, Andrade Filho JD, Falcão AL, Brazil RP 2003. Estudo de flebotomíneos (Diptera, Psychodidae) na zona urbana da Cidade de Campo Grande, Mato Grosso do Sul, Brasil, 1999-2000. Cad Saude Publica 19: 933-944.
Oliveira AG, Galati EAB, de Oliveira O, de Oliveira GR, Espindola IAC, Dorval MEC, Brazil RP 2006a. Abundance of Lutzomyia longipalpis (Diptera: Psychodidae: Phlebotominae) and urban transmission of visceral leishmaniasis in Campo Grande, state of Mato Grosso do Sul, Brazil. Mem Inst Oswaldo Cruz 101: 869-874.

Oliveira ALL, Paniago AMM, Dorval MEC, Oshiro ET, Leal CR, Sanches M, Cunha RV, Bóia MN 2006b. Foco emergente de leishmaniose visceral em Mato Grosso do Sul. Rev Soc Bras Med Trop 39: 446-450.

Oliveira EF, Silva EA, Fernandes CES, Paranhos Filho AC, Gamarra RM, Ribeiro AA, Brazil RP, de Oliveira AG 2012. Biotic factors and occurrence of Lutzomyia longipalpis in endemic area of visceral leishmaniasis, Mato Grosso do Sul, Brazil. Mem Inst Oswaldo Cruz 107: 396-401.

Peterson AT, Nakazawa Y 2008. Environmental data sets matter in ecological niche modelling: an example with Solenopsis invicta and Solenopsis richteri. Glob Ecol Biogeogr 17: 135-144.

Peterson AT, Pereira RS, Neves VFC 2004. Using epidemiological survey data to infer geographic distributions of leishmaniasis vector species. Rev Soc Bras Med Trop 37: 10-14.

Peterson AT, Shaw J 2003. Lutzomyia vectors for cutaneous leishmaniasis in Southern Brazil: ecological niche models, predicted geographic distributions and climate change effects. Int J Parasitol 33: 919-931.

Phillips SJ, Anderson RP, Schapire RE 2006. Maximum entropy modeling of species geographic distributions. Ecol Model 190: 231-259.

Quintana M, Salomón O, Guerra R, de Grosso ML, Fuenzalida A 2013. Phlebotominae of epidemiological importance in cutaneous leishmaniasis in northwestern Argentina: risk maps and ecologic niche models. Med Vet Entomol 27: 39-48.

Romero GA, Boelaert M 2010. Control of visceral leishmaniasis in Latin America - a systematic review. PLoS Negl Trop Dis 4: e584.

Salomón OD, Basmajdian Y, Fernández MS, Santini MS 2011. Lutzomyia longipalpis in Uruguay: the first report and the potential of visceral leishmaniasis transmission. Mem Inst Oswaldo Cruz 106: $381-382$

Santos SO, Arias J, Ribeiro AA, de Paiva Hoffmann M, de Freitas RA, Malacco MA 1998. Incrimination of Lutzomyia cruzi as a vector of American visceral leishmaniasis. Med Vet Entomol 12: 315-317.

Sarkar S, Strutz SE, Frank DM, Rivaldi C-L, Sissel B, Sanchez-Cordero V 2010. Chagas disease risk in Texas. PLoS Negl Tropl Dis 4: e 836.

Sherlock IA 1996. Ecological interactions of visceral leishmaniasis in the state of Bahia, Brazil. Mem Inst Oswaldo Cruz 91: 671-683.

Silva EA, Andreotti R, Honer MR 2007. Comportamento de Lutzomyia longipalpis, vetor principal da leishmaniose visceral americana em Campo Grande, estado de Mato Grosso do Sul. Rev Soc Bras Med Trop 40: 420-425.

Souza GD, Santos ED, Andrade-Filho JD 2009. The first report of the main vector of visceral leishmaniasis in America, Lutzomyia longipalpis (Lutz and Neiva) (Diptera: Psychodidae: Phlebotominae), in the state of Rio Grande do Sul, Brazil. Mem Inst Oswaldo Cruz 104: 1181-1182.

Ximenes MFM, Castellon EG, Souza MF, Freitas RA, Pearson RD, Wilson ME, Jerônimo SMB 2000. Distribution of Phlebotomine sandflies (Diptera: Psychodidae) in the state of Rio Grande do Norte, Brazil. J Med Entomol 37: 162-169.

Zeilhofer P, Kummer OP, dos Santos ES, Ribeiro ALM, Missawa NA 2008. Spatial modelling of Lutzomyia (Nyssomyia) whitmani s.l. (Antunes \& Coutinho, 1939) (Diptera: Psychodidae: Phlebotominae) habitat suitability in the state of Mato Grosso, Brazil. Mem Inst Oswaldo Cruz 103: 653-660. 